\title{
GENETIC DIVERSITY AND RELATIONSHIPS AMONG 15 SPECIES OF IRIS BASED ON AMPLIFIED FRAGMENT LENGTH POLYMORPHISM MARKERS
}

\author{
XU, Y. F. ${ }^{1}-$ HuSSAIN, K. ${ }^{2}-$ YAn, X. F. ${ }^{3}-$ ChEn, X. H. ${ }^{1}-$ ShaO, M. N. ${ }^{1}-$ GuAN, P. ${ }^{1}-$ QU, B..$^{1 *}$ \\ ${ }^{1}$ College of Bioscience and Biotechnology, Shenyang Agricultural University \\ NO. 120 Dongling Street, Shenyang, Liaoning, China \\ ${ }^{2}$ Department of Botany, University of Gujrat HH Campus, Gujrat, Pakistan
}

${ }^{2}$ Shuwen Biotech CO., LTD, NO. 139-1 Wenhua Road, Shenyang, Liaoning, China

${ }^{*}$ Corresponding author

e-mail: syau_qb@163.com

(Received $18^{\text {th }}$ Oct 2018; accepted $2^{\text {nd }}$ Jan 2019)

\begin{abstract}
Irises are among the most well-known ornamental flowers in the world. There are probably over 60 species of Iris in China, accounting for approximately one-fifth of the world's wild resources; however, there is little information available on the genetic diversity and relationships among these species. We accordingly studied the genetic diversity and relationships among 15 species of Iris collected in China using amplified fragment length polymorphism (AFLP) markers in conjunction with a combination of EcoRI/MseI restriction enzymes. A total of 378 clear and stable bands with sizes ranging from 50 to $800 \mathrm{bp}$ were obtained using 9 pairs of primers screened from 64 primer combinations; the percentage of polymorphic bands was $99.74 \%$. Some species - I. setosa, I. uniflora, I. dichotoma, I. typhifolia, I. ventricosa, and I. japonica - were differentiated by just a single specific band, and these band patterns were used for identification. An assessment of genetic diversity parameters using AFLP markers showed that Iris has high genetic diversity at the species level. Clustering analysis and principal coordinate analysis showed that the 15 species of Iris were genetically similar, and thus related. When the genetic similarity coefficient was 0.55 , the 15 species could be divided into five distinct groups. The aforementioned results will verify, replenish, and consummate the classical taxonomy and systematology of Iris, and also provide references for the conservation, management, classification, identification, and breeding of Iris resources.
\end{abstract}

Keywords: Iris, AFLP, genetic diversity, relatedness, conservation

\section{Introduction}

The genus Iris, belonging to the family Iridaceae, includes more than 300 species of perennial and herbaceous plants. They are distributed mainly in northern temperate zones such as Asia, Europe, and North America. Among the 300 plus species, there are 60 species, 13 varieties, and 5 variants that are native to China, and these are principally distributed in the northwest, southwest, and northeast of China (Zhao, 1985; Waddick, 1992). The elegant flowers of Iris can be found in a breathtaking array of colors, ranging from white, yellow, and orange, through every tone of blue, purple, pink, and brown, to black. Iris species also produce beautiful linear foliage (Claire, 1957; Bailly, 2001). These perfect characteristics make irises one of the most favored ornamental plants. Because of their simple cultivation, extensive management, and low maintenance costs, species of Iris are widely utilized in landscaping. Additionally, because of their high resistance to cold, drought, disease, and salinity, some species, such as Iris lactea, Iris sanguinea, and Iris halophila, can be applied for improving coast and saline-alkaline land (Bai et al., 2008). In addition, Iris tectorum, 
Belamcanda sinensis, Iris germanica, and a few other species have medicinal value, containing flavonoids with good detoxification effects (Agarwal et al., 1984; Burcu et al., 2014). Understanding the genetic diversity and relationships among plant species and varieties is very important for breeding and intellectual property rights (IPR) (Tay et al., 2006; Wanjala et al., 2013). Iris breeding began very early in Europe. Further, by crossbreeding, many new cultivars with desirable traits have been bred by using the extensive collections of wild species and varieties. Embryo culture, somatic hybridization, and transgenic breeding are a few other successful methods used for Iris breeding (Shimizu et al., 1999). Up until 2009, there were more than 30000 Iris cultivars in the world, as catalogued by the American Iris Association (Zhang, 2010). In China, wild Iris resources with many good genes are abundant, and these may be used to improve, innovate, and preserve the Iris germplasm. However, Iris breeding started late and developed relatively slowly in China. Only a small part of the Iris resource is utilized directly without any modification, probably due to the lack of systematic research. Further, each year many new cultivars are being introduced, which represents a considerable annual expense. In breeding programs, breeders typically select parents with good performance and a wide hereditary basis, according to their genetic diversity and relatedness to parental germplasm, which are very important criteria for crossbreeding (Hesham et al., 2010; Matus et al., 2002). The classification of the genus Iris has been controversial, because of the focus on botany and horticulture. In recent years, the classification system of the American Iris Society, which is based on traditional morphological characteristics, has become popular (Lin et al., 2010). However, morphological classification has certain disadvantages, which often leads to an incorrect evaluation. The morphological characteristics of plants may be expressed differently in different environments, and can only sometimes be appraised correctly in adult plants, which could result in a waste of resources for plant growth and increase the difficulty of evaluation (Poppendieck, 1983; Vieira et al., 2007). Thus, the classification of Iris is vague and often invalid in practice. Consequently, it is not surprising to find different cultivars with the same name or to find the same plant referred to by different names (Zhang et al., 2008).

Because of the various species and relatively similar traits, confusion and misuse of Iris resources can easily occur. Therefore, it is important that a scientific and reliable identification method be established. With the continuous development of molecular biology techniques, several studies of Iris have been conducted at the molecular level. Over the past few decades, DNA-based markers have proven to be very successful in classifying plants (Vos et al., 1995; Qiao, 2007), and in assessing the intraspecific and interspecific genetic diversity of plants (Morales et al., 2013). Although some studies have been conducted on the genetic relationships and population genetic diversity among species or cultivars of Iris (Tang et al., 2010; Chung et al., 2014), because of the diversity of natural geographical distribution, only a few species have been studied, and the phylogenetic relationships of many other species in this genus is still currently unclear or disputed and needs to be further clarified.

Amplified fragment length polymorphism studies have been used extensively to examine genetic population structure and provide guidance for conservation efforts. AFLP is a molecular marker technology with high-integrated utility, which combines the advantages of RFLP and RAPD. Due to the characteristics of the required trace levels of DNA, high polymorphism levels, good reproducibility, high stability, ease of standardization, genome-wide marker distribution, and no prior sequence knowledge, 
the AFLP method is considered to be a better tool for evaluating the genetic diversity (Jianab et al., 2009; Garrido et al., 2012) and genetic structure (Breinholt et al., 2009) of plants, and for plant genotyping (Allen et al., 2008) and DNA fingerprinting (Tatikonda et al., 2009) analyses. In addition, AFLP analysis is credibly applied to assessing the genetic diversity of intraspecies and interspecies (Umezuruike et al., 2010; Isaza et al., 2012; Hong et al., 2013).

In this study, using AFLP markers, we objectively evaluated the genetic diversity and genetic relationships of 15 wild Iris samples collected in northern China. The objectives of this study were to (1) verify, replenish, and consummate the classical taxonomy and systematology of Iris, and (2) provide references for the conservation, management, classification, identification, and breeding of Iris resources.

\section{Materials and Methods}

\section{Sampling of species}

In this study, 15 species of Iris were collected and analyzed (Table 1 and Fig. 1). The field studies did not involve endangered or protected species, and no specific permissions were required for the locations collected from. All plants were wild species and mainly obtained from northern China. Leaves of each species were taken outdoors, dried with silica gel, and stored in ziplock bags at room temperature for DNA extraction.

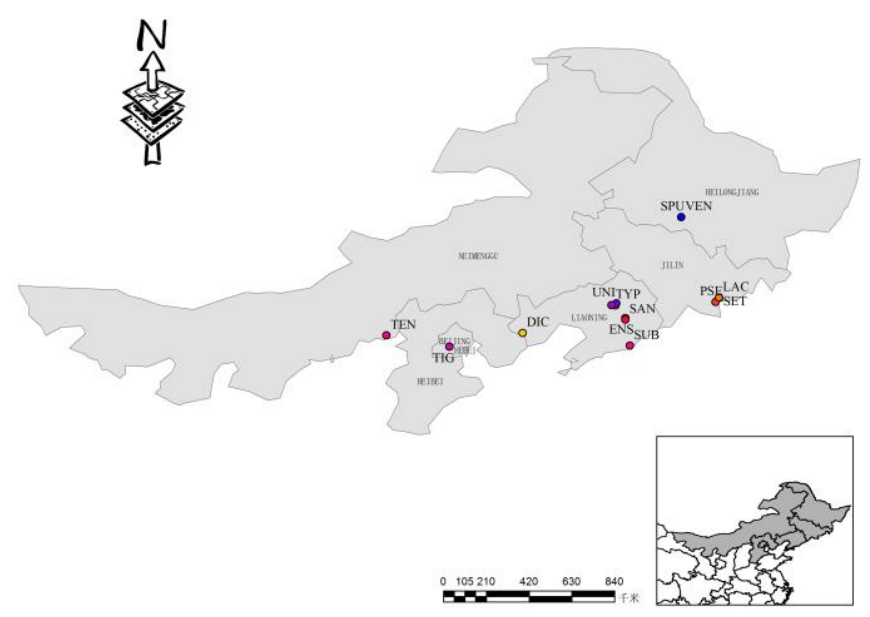

Figure 1. Locations of sampling sites of 15 species of Iris in North China

\section{AFLP analysis}

Genomic DNA was extracted from dried leaves using the CTAB method described by Wang et al. with some modifications (Wang et al., 2013). PVP was added when DNA extracted because there was more phenolics and flavonoids in leaves of Iris, and DNA extraction numbers were increased. The samples were initially ground with a pestle and mortar, and then with magnetic particles, without liquid nitrogen. The concentration and purity of genomic DNA were determined by agarose gel electrophoresis (1\%) and UV spectrophotometry. Finally, the genomic DNA was diluted to a concentration of $50 \mathrm{ng} / \mu \mathrm{l}$ and stored at $-20^{\circ} \mathrm{C}$ for AFLP analysis. 
The AFLP reactions and procedures were performed according to the methods of Vos et al. (1995) and Chen et al. (2009) with some modifications. Genomic DNA was digested using an enzyme combination of EcoRI (Fermentas) and MseI (Sangon). Three species of Iris were selected randomly from the 15 Iris accessions for primer screening, namely I. setosa (Jilin), I. lactea var. chinensis (Liaoning), and I. ventricosa (Heilongjiang). Nine primer combinations and 64 AFLP primer pairs could amplify clear and reproducible polymorphic bands. AFLP-PCR products were separated by $6 \%$ denaturing polyacrylamide gel electrophoresis, with constant power of $55 \mathrm{~W}$ for approximately $2 \mathrm{~h}$, and then the DNA bands were visualized by silver staining and imaged using a scanner.

Table 1. List of species of Iris included in the study

\begin{tabular}{|c|c|c|c|c|}
\hline Name & Species code & Sample size & Location & Habitats \\
\hline Iris setosa Pall. ex Link & SET & 20 & $\begin{array}{l}\text { Changbaishan, Jilin, } \\
\text { 128.193479,42.190904 }\end{array}$ & marshland \\
\hline $\begin{array}{l}\text { I. lactea } \text { Pall. var. chinensis } \\
\text { (Fisch.)Koidz. }\end{array}$ & LACV & 22 & $\begin{array}{c}\text { Tianzhushan, Shenyang, Liaoning, } \\
123.606614,41.84861\end{array}$ & waste land \\
\hline I. pseudacorus $\mathrm{L}$. & PSE & 22 & $\begin{array}{c}\text { Changbaishan, Jilin, } \\
128.021804,42.004753\end{array}$ & waterside \\
\hline I. spuria $\mathrm{L}$. & SPU & 20 & $\begin{array}{c}\text { Haerbin, Heilongjiang } \\
126.50726,45.79324\end{array}$ & patana \\
\hline I. tenuifolia Pall. & TEN & 25 & $\begin{array}{c}\text { Bayintu,Fengzhen, Inner Mongolia, } \\
113.505159,40.505955\end{array}$ & Sandy meadow \\
\hline I. ensata Thunb. & ENS & 24 & $\begin{array}{c}\text { Benxi, Liaoning, } \\
124.045916,41.280213\end{array}$ & marshland \\
\hline I. uniflora Pall. ex Link & UNI & 20 & $\begin{array}{c}\text { Qipanshan, Shenyang, Liaoning, } \\
123.642905,41.943596\end{array}$ & patana \\
\hline I. dichotoma Pall. & DIC & 20 & $\begin{array}{c}\text { Jianchang, Huludao, Liaoning, } \\
119.513145,40.61749\end{array}$ & patana \\
\hline I. sanguinea Donn ex Horn. & SAN & 22 & $\begin{array}{c}\text { Benxi,Liaoning } \\
124.047784,41.21838\end{array}$ & marshland \\
\hline I. typhifolia Kitagawa & TYP & 22 & $\begin{array}{c}\text { Beiling Garden,Shenyang, Liaoning, } \\
123.43881,41.860968\end{array}$ & waterside \\
\hline I. ventricosa Pall. & VEN & 20 & $\begin{array}{l}\text { Haerbin, Heilongjiang } \\
126.504816,45.792134\end{array}$ & Sandy meadow \\
\hline I. lactea Pall. & LAC & 20 & $\begin{array}{c}\text { Changbaishan, Jilin } \\
128.171363,42.195006\end{array}$ & patana \\
\hline I. japonica Thunb. & JAP & 23 & $\begin{array}{c}\text { Wanshoushan,Beijing } \\
116.281049,40.006067\end{array}$ & forest edge \\
\hline I. tigridia Bunge & TIG & 25 & $\begin{array}{c}\text { Qianshan,Anshan,Liaoning } \\
116.281049,40.006067\end{array}$ & patana \\
\hline I. subdichotoma Y. T. Zhao & SUB & 24 & $\begin{array}{c}\text { Dandong ,Liaoning } \\
124.246351,40.05011\end{array}$ & patana \\
\hline
\end{tabular}




\section{Data analysis}

Amplified AFLP bands were scored as present (1) or absent (0) by visual inspection. Data entry in Excel created a 0/1 binary matrix, based on which we could calculate the number and percentage of polymorphic bands (PPB). Clustering analysis and principal component analysis (PCA) were then performed using NTSYS-pc (version 2.10e) software (Rohlf, 2000). The parameters of the differential degree and the genetic diversity among species of Iris were calculated using popgene32 (version 1.32) software (Yeh, 1997), including genetic similarity coefficient, genetic distance, the observed number of alleles $(\mathrm{Na})$, the effective number of alleles $(\mathrm{Ne})$, Nei's genetic diversity index $(\mathrm{H})$, and Shannon's information index of diversity (I). All of the aforementioned calculations were performed based on the assumption that these species were in Hardy-Weinberg equilibrium.

\section{Results}

\section{Polymorphism of amplified fragments}

An AFLP amplification map was obtained using 9 pairs of primers for 15 species of Iris. A total of 378 generated bands were clear and stable, ranging in size from 50 to $800 \mathrm{bp}$, of which 377 bands (99.74\%) were polymorphic (Table 2). The number of bands amplified per primer combination ranged from 34 to 53, with an average of 42, and the average number of polymorphic bands per primer pair was 41.89. The polymorphic percentage of bands per primer combination was close to $100 \%$, showing that the 15 species of Iris have rich genetic diversity.

Furthermore, genetic diversity parameters (Table 3) demonstrated that the genus Iris has considerable genetic diversity at the species level. Because of the lack of gene flow among species, not only can these species be used as good breeding materials, but they should also be protected as wildlife resources.

Table 2. Amplified fragment length polymorphism (AFLP) detected using nine primer pairs for 15 species of Iris

\begin{tabular}{c|c|c|c}
\hline Primer pairs & Total amplified bands & $\begin{array}{c}\text { Number of } \\
\text { polymorphic bands }\end{array}$ & $\begin{array}{c}\text { Percentage of polymorphic } \\
\text { bands (PPB \%) }\end{array}$ \\
\hline E-AAG/M-CTA & 34 & 34 & 100.00 \\
E-AAC/M-CAG & 38 & 38 & 100.00 \\
E-AAC/M-CAA & 36 & 36 & 100.00 \\
E-AAC/M-CAT & 40 & 39 & 97.50 \\
E-AGG/M-CTG & 45 & 45 & 100.00 \\
E-AGC/M-CTA & 47 & 47 & 100.00 \\
E-ACT/M-CAT & 53 & 53 & 100.00 \\
E-ACT/M-CAC & 46 & 46 & 100.00 \\
E-ACT/M-CTG & 39 & 39 & 100.00 \\
Sum & 378 & 377 & 99.74 \\
Mean & 42 & 41.89 & 99.74 \\
\hline
\end{tabular}


Table 3. Amplified fragment length polymorphism (AFLP) genetic diversity parameters of 15 species of Iris

\begin{tabular}{c|c|c|c|c}
\hline Parameters & $\mathbf{N a}^{\mathbf{a}}$ & $\mathbf{N e}^{\mathbf{b}}$ & $\mathbf{H}^{\mathbf{c}}$ & $\mathbf{I}^{\mathbf{d}}$ \\
\hline Mean & 1.9974 & 1.7950 & 0.4319 & 0.6193 \\
SD & 0.0514 & 0.2257 & 0.0890 & 0.1033 \\
\hline
\end{tabular}

${ }^{\text {a} O b s e r v e d ~ n u m b e r ~ o f ~ a l l e l e s ; ~ ' E f f e c t i v e ~ n u m b e r ~ o f ~ a l l e l e s ; ~ ' N e i ' s ~ g e n e ~ d i v e r s i t y ; ~ ' S h a n n o n ' s ~}$ information index

Many specific bands were displayed by 0/1 binary matrix analysis (Table 4). For example, among the amplification products of primer combination E-AAG/M-CTA, the first band was absent from I. japonica, and among the amplification products of primer pair E-AAC/M-CAG, the 26th band was present in I. dichotoma.

Table 4. Specific bands and identification methods of 15 species of Iris

\begin{tabular}{|c|c|c|c|c|c|c|c|c|c|}
\hline \multirow[b]{2}{*}{ Sample } & \multicolumn{9}{|c|}{ Primers } \\
\hline & $\begin{array}{l}\text { E-AAG } \\
\text { /M-CTA }\end{array}$ & $\begin{array}{l}\text { E-AAC } \\
\text { /M-CAG }\end{array}$ & $\begin{array}{c}\text { E-AAC } \\
\text { /M-CAA }\end{array}$ & $\begin{array}{l}\text { E-AAC } \\
\text { /M-CAT }\end{array}$ & $\begin{array}{l}\text { E-AGG } \\
\text { /M-CTG }\end{array}$ & $\begin{array}{l}\text { E-AGC } \\
\text { /M-CTA }\end{array}$ & $\begin{array}{l}\text { E-ACT } \\
\text { /M-CAT }\end{array}$ & $\begin{array}{l}\text { E-ACT } \\
\text { /M-CAC }\end{array}$ & $\begin{array}{c}\text { E-ACT } \\
\text { /M-CTG }\end{array}$ \\
\hline SET & & $8(1), \mathbf{3 1}(\mathbf{1})$ & & & $21(0)$ & & $44(0)$ & & \\
\hline LACV & & $1(1), 2(1), 4(1), 38(1)$ & & & & & & & \\
\hline PSE & & & & $29(0)$ & & & & $26(1)$ & \\
\hline SPU & & & & & & & & & $38(0)$ \\
\hline TEN & & & $26(1)$ & & & & $37(1)$ & & \\
\hline ENS & & & $18(1)$ & & & & $37(1)$ & & \\
\hline UNI & $9(1), 10(1)$ & $2(1), 8(1)$ & 28(1) & $24(0)$ & & & & & \\
\hline DIC & & $5(1), 7(1), 26(1), 38(1)$ & & & & & & & 31(0),39(0) \\
\hline SAN & $9(1), 10(1)$ & $1(1)$ & & & & & $47(1)$ & & \\
\hline TYP & & $16(1)$ & $36(1)$ & $15(0)$ & & & & $26(1)$ & \\
\hline VEN & & 3(1),4(1),16(1) & & & $21(0)$ & & $11(0)$ & & \\
\hline LAC & & & & & $21(0)$ & & & & \\
\hline JAP & $1(0)$ & & & & & $42(1)$ & $11(0), 47(1)$ & & $38(0), 39(0)$ \\
\hline TIG & & $5(1), 7(1)$ & & $15(0)$ & & & & & \\
\hline SUB & & & & $29(0)$ & & & & & \\
\hline
\end{tabular}

The bold numbers indicate a specific band per species that can be distinguished using only this band. A (B) means that the A band is present (1) or absent (0) in decreasing molecular weight (50-800 bp) of a primer amplification product. B has only two values-0 and 1. E.g., 9(1) ${ }^{\mathrm{a}}$ under the primer pair E-AAG/M-CTA means that the band of Iris sanguinea appears in E-AAG/M-CTA amplified products at the ninth position by decreasing molecular weight 
Moreover, different species of Iris can be distinguished by these specific bands. Some species-I. setosa, I. uniflora, I. dichotoma, I. typhifolia, I. ventricosa, and I. japonica-were differentiated by just a single specific band. Nevertheless, some species were differentiated by more than one specific band. In I. pseudacorus for instance, the $29^{\text {th }}$ band was absent in the amplification products of primer combination E-AAC/M-CAT, but the $26^{\text {th }}$ band was present among the amplification products of primer combination E-ACT/M-CAC.

\section{Genetic similarity coefficient analysis}

In taxonomy, the genetic similarity coefficient or Nei's genetic identity refers to a similarity index between two taxonomic units and is sometimes replaced by genetic distance, which is a complement parameter of the genetic similarity coefficient. The genetic similarity coefficient generally lies between 0 and 1 (Li et al., 2011). For Iris, the genetic similarity coefficient ranged from 0.4392 to 0.6296 (Table 5), and that between I. tenuifolia and I. uniflora (approx. 0.4392) was the smallest. The genetic similarity coefficient between I. setosa and I. tenuifolia (approx. 0.6296) was the largest. The genetic distance reflects the degree of genetic differentiation between species. The genetic distance in Iris ranged from 0.4626 to 0.8229 , with the genetic distance between I. setosa and I. tenuifolia (approx. 0.4626) being the smallest, and that between I. tenuifolia and I. uniflora being the largest (approx. 0.8229). All other genetic distances indicated that the genus Iris has substantial genetic differentiation at the species level.

Table 5. Nei's genetic identity (above diagonal) and genetic distance (below diagonal)

\begin{tabular}{|c|c|c|c|c|c|c|c|c|c|c|c|c|c|c|}
\hline & ET & LACV & PSE & SPU & TEN & ENS & UNI & DIC & SAN & TYP & VEN & LAC & JAP & TIG SUB \\
\hline SE & & & & & & & & 0.56 & & & & & & 0 . \\
\hline $\mathrm{ACV}$ & & & & & & & & 0.5 & & & & & & \\
\hline PSE & 6168 & & $* * * *$ & & & & 0.4868 & 0.4 & 0 & & & & & 0.5767 \\
\hline $\mathbf{U}$ & 0 & & & & & & & & & & & & & 0.6 \\
\hline & 4626 & & & & & & & & c & & & & & \\
\hline ENS & & 0.58 & 0.4968 & & & $* * * *$ & & 0.5 & 0.5 & & & & & 90.5503 \\
\hline UNI & & & & & & & & 0 & 0 & & & & & \\
\hline DIC & 3 & 0.6 & 0.6 & & & & & $* * * *$ & 0.5212 & 0.5 & & & & 0. \\
\hline SAN & 0.6022 & & 0.7 & 0.6 & & 0.6 & 0.6 & 0.6517 & $* * * *$ & 0.5582 & & & & 265 \\
\hline TYP & 0.7874 & & & 0 & 0. & 0. & 0. & 0. & 0 & $* * * *$ & & & & 120.5238 \\
\hline VEN & 0.6879 & 0.5 & 0.7 & 0.6070 & 0.6670 & 0.6879 & 0.6366 & 0.6 & 0.5 & 0.5 & $* * * *$ & & & 0. \\
\hline LAC & 0.5689 & 0. & 0.6 & 0.5 & 0.5 & 0.6366 & 0.6670 & 0.6 & 0.6 & 0.6 & 0.6266 & $* *$ & & 820 \\
\hline JAP & 0.7145 & 0.6266 & 0.6119 & 0.5643 & 0.5926 & 0.5643 & 0.6316 & 0.7364 & 0.68 & 0.6316 & 0.67 & 0 & $* * * *$ & 0.57670 .5000 \\
\hline TIG & 0.5736 & 0.5596 & 0.527 & 0.4753 & 0.4925 & 0.5926 & 0.6119 & 0.6316 & 0.64 & 0.6517 & 0.63 & 0.6 & 0.5504 & $* * * * 0.5106$ \\
\hline SUB & 7091 & & & 0.7 & 0.6 & 0.5 & 0.7200 & 0.5 & 5 & 0.6466 & 0. & & & $0.6722 *$ \\
\hline
\end{tabular}




\section{Clustering analysis and principal component analysis}

Based on the genetic similarity coefficient, genetic relationships among the 15 species of Iris were examined by clustering analysis using the UPGMA method (Fig. 2). When the genetic similarity coefficient was 0.55 , the species could be divided into five groups: the first group: I. dichotoma and I. subdichotoma, belonging to Subgen. Pardanthopsis; the second group: I. pseudacorus (Subgen. Limniris Sect. Limniris), I. ensata (Subgen. Limniris Sect. Limniris), I. spuria (Subgen. Xyridion), I. tigridia (Subgen. Iris Sect. Hexapogon), and I. japonica (Subgen. Crossiris Sect. Crossris); the third group: I. tenuifolia, I. setosa, I. lactea var. chinensis, and I. lacteal, all belonging to Subgen. Limniris Sect. Limniris; the fourth group: I. sanguinea, I. ventricosa, I. typhifolia, all belonging to Subgen. Limniris Sect. Limniris; and the fifth group: I. uniflora ( Subgen. Limniris Sect. Loniris).

In addition, a further partition was noted when considering the genetic similarity coefficient of 0.59 . The first group had two sub-groups: I. dichotoma and I. subdichotoma. The second group could be divided into three sub-groups: I. pseudacorus; I. ensata, I. spuria, and I. tigridia; and I. japonica. The third group had two sub-groups: I. tenuifolia and I. setosa; and I. lactea var. chinensis and I. lacteal. The fourth group had three sub-groups: I. sanguinea, I. ventricosa, and I. typhifolia.

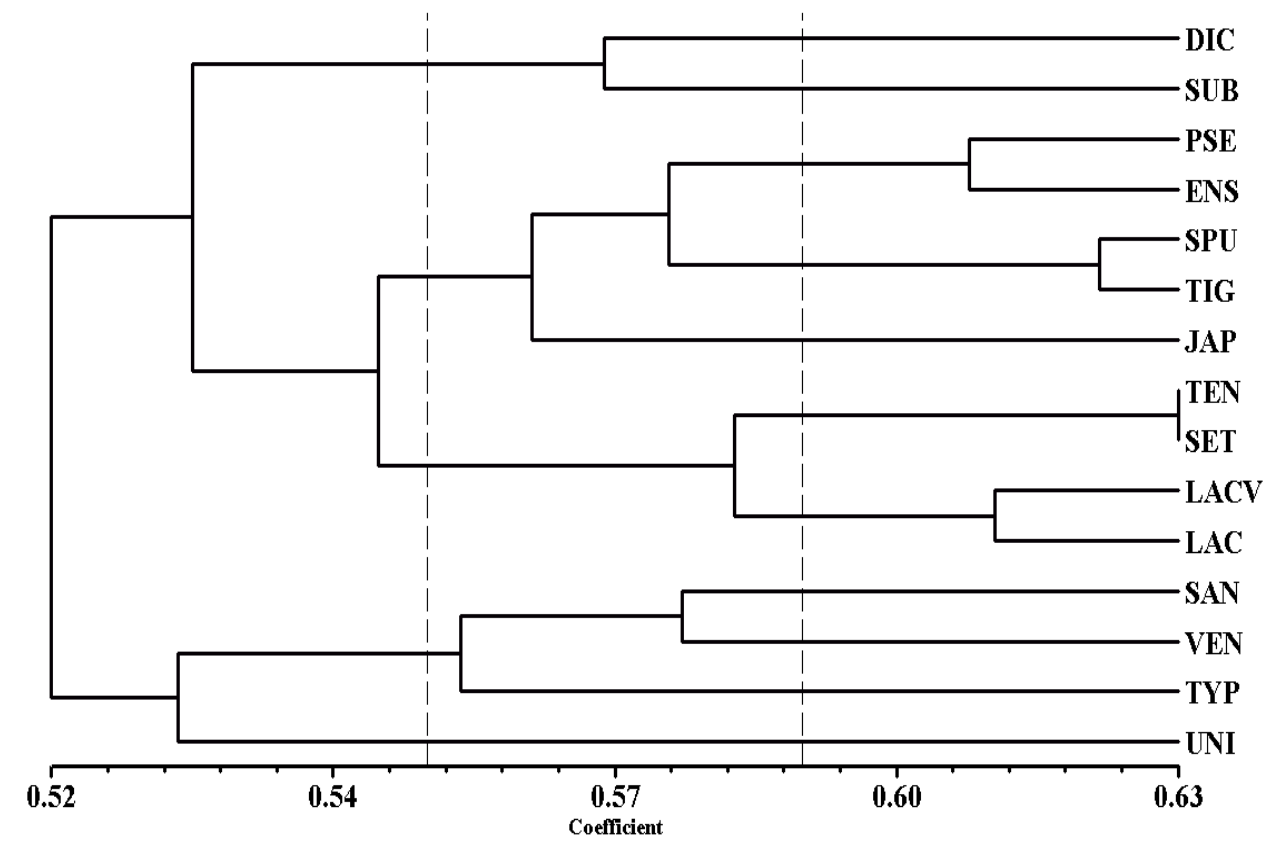

Figure 2. Phylogenetic analysis of 15 species of Iris based on AFLP markers

PCA of the 15 species of Iris based on the genetic similarity coefficient using NTsys2.10e software (Fig. 3) gave an important insight into their genetic relationships. The relationships among species showed a positive correlation with the genetic distance, and species close to each other on the shadow (Fig. 3a) were classified together (Fig. 3b), showing that the PCA and clustering analysis provided similar results when analyzing relationships. Therefore, PCA could be used to explain and verify the clustering results, which were similar to those reported by Huang et al. (2009). 

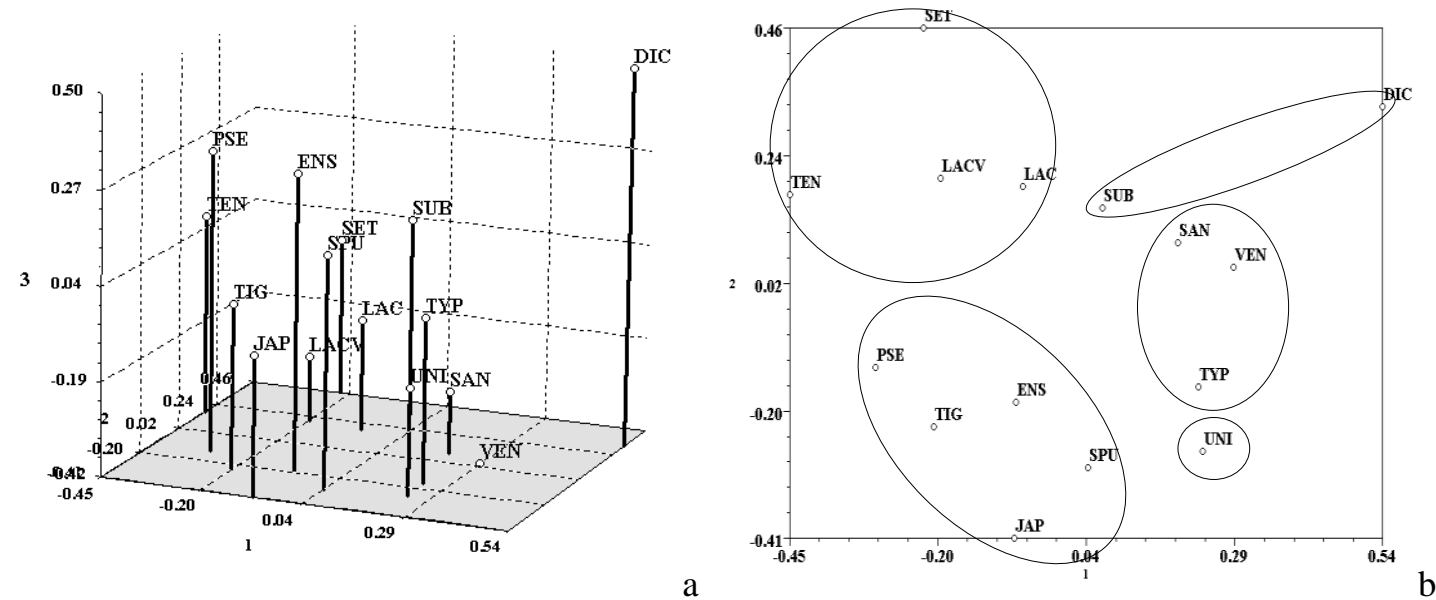

Figure 3. Principal coordinates analysis (PCA) of 15 species of Iris by AFLP markers. Fig. $3 a$ is a 3D-plot, of which Fig. $3 b$ is a 2D-plot with dimension 1 and dimension 2

\section{Discussion}

At present, the genetic diversity of many plants has been studied using molecular markers, including AFLP, SRAP, RAPD, ISSR, and SSR (Duffy et al., 2009; Bertoni et al., 2010; Talebi et al., 2011). Here, a total of 378 bands were obtained from 15 species of Iris using AFLP markers with 9 pairs of primers. The percentage of polymorphic bands was $99.74 \%$, and the length of amplified fragment was approximately 50-800 bp. A combined analysis of genetic diversity parameters $(\mathrm{Na}, \mathrm{Ne}, \mathrm{H}, \mathrm{I})$ and genetic distance with the polymorphism of amplified fragments showed that the genus Iris has a rich genetic diversity and that there is relatively large genetic differentiation at the species level. Thus, it is important to use Iris wildlife resources for crossbreeding, as well as for ornamental and medicinal purposes. In addition, our results can assist in making effective decisions for the conservation of the germplasm of this species. The samples used in this study were all wild species, which may be one reason for the high genetic differentiation.

We found that different species of Iris had some specific bands, which can be reasonably used for identification. The morphological method and molecular marker method can be used together to accurately identify the species of Iris. In addition, the specific alleles will aid the assessment of stability and purity of genotypes in breeding and seed reproduction programs. Further, members of the genus Iris lacked mutual bands and there was a high specificity among species.

On the basis of soil and water requirements, Iris is divided into three categories (Liu et al., 2009): the first category includes species that prefer weakly alkaline, calcareous, damp, fertile, and well-drained soil, such as Iris tectorum Maxim. and I. germanica; the second category includes species that thrive in acidic and wet soil, such as I. japonica and I. pseudacorus; the third category includes species that adapt to any type of soil-poor, dry, or wet-such as I. lactea var. chinensis. In our study, I. spuria and I. tigridia in the second group belong to two different subgenera in the morphological classifications Subgen. Xyridion and Subgen. Iris, respectively. They grow in any soil and have strong adaptability, which contributes to explaining why I. spuria and I. tigridia clustered together. 
On the basis of morphological systematics, the genus Iris is divided into six subgenera as recorded in the "Flora of China": Limniris, Xyridion, Nepalensis, Pardanthopsis, Crossiris, and Iris (Zhao, 1985). The results obtained in this study are somewhat inconsistent with the classification mentioned above. For example, Limniris species occur in the second, third, fourth, and fifth groups. Therefore, Subgen. Limniris is a very unnatural group, and should be divided into several groups or subgenera, which would be more reasonable from the tree diagram analysis and is consistent with the viewpoint of Mou et al. (2011).

The principal components analysis (PCA) revealed some aspects of relationships that were not recognizable by clustering analysis (Marak et al., 2010). We also applied PCA for better presentation of the relationships among the species of Iris. I. dichotoma was distant from the others, and therefore it seems unreasonable that I. dichotoma and I. subdichotoma are clustered together. Since I. uniflora is clustered close to I. typhifolia, it should not be classified into the fifth group by itself.

In the Iris relationship analysis based on AFLP, we found that there were inconsistencies between the molecular marker method and the traditional method of classification, and sometimes there was no correspondence between the methods. Perhaps because the polymorphism of AFLP markers reflects differences in complex genomic DNA at the molecular level, whereas morphological traits are the results of certain functional gene expressions mediated by external environmental effects. Differences in DNA content may not be reflected in morphology, since some genes may remain unexpressed. Therefore, the genetic relationship and classification of Iris species should be assessed correctly and reasonably using the morphological method combined with the molecular marker method.

An understanding of the levels and patterns of genetic diversity is important for designing better conservation and improved management strategies for threatened and endangered species. Although the Iris samples collected in this work have a rich genetic diversity, considerable exploitation of the wild resources together with habitat destruction have led to a loss of Iris germplasm genetic diversity. Some wild Iris are difficult to collect because they have become rare. In order to actively protect wild plants of the Iris genus, wild plant germplasm nurseries have been established in many botany garden, which will provide the necessary genetic basis for breeding new species. The study on genetic diversity among 15 species of Iris based on AFLP marker will further identify relationships among species in molecular level. This results combined with morphological systematic, will be useful to breeders in selecting the best parental combinations for Iris breeding program in China.

\section{Conclusion}

In conclusion, AFLP markers were shown to be a good tool for assessing genetic diversity, genetic relationships, and identifications in Iris. The high percentage (99.74\%) of polymorphic bands, genetic diversity parameters $(\mathrm{Na}, \mathrm{Ne}, \mathrm{H}, \mathrm{I})$, and genetic distances showed that the genus Iris has a rich genetic diversity and relatively large genetic differentiation at the species level. The 15 Iris species analyzed in this study can be divided into five groups and separated from each other by a few primer combinations. These results will be useful for the conservation, management, classification, identification, and breeding of Iris resources. 
Acknowledgements. This study was supported by national public welfare industry (agriculture) research special funds and the Shenyang Science and Technology Bureau.

\section{REFERENCES}

[1] Agarwal, V. K., Thappa, R. K., Agarwal, S. G. (1984): Isoflavones of two Iris species. Phytochemistry 23: 2703-2704.

[2] Allen, G., Williams, A., Rabinowicz, P. D. (2008): Worldwide genotyping of castor bean germplasm (Ricinus communis L.) using AFLPs and SSRs. - Genet Res Crop Evol. 55: 365-378.

[3] Bai, W. B., Li, P. F., Li, B. G. (2008): Some physiological responses of Chinese Iris to salt stress. - Pedosphere 18: 454-463.

[4] Bailly, C., Corbineau, F., Van Doorn, W. G. (2001): Free radical scavenging and senescence in Iris tepals. - Plant Physiol Biochem. 39: 649-656.

[5] Bertoni, B. W., de C Telles, M. P., Malosso, M. G. (2010): Genetic diversity in natural populations of Jacaranda decurrens Cham. determined using RAPD and AFLP markers. Genet Mol Biol 33: 532-538.

[6] Breinholt, J. W., Van Buren, R., Kopp, O. R. (2009): Population genetic structure of an endangered Utah endemic, Astragalus ampullarioides (Fabaceae). - Am J Bot. 96: 661-667.

[7] Burcu, B., Aysel, U., Nurdan, S. (2014): Antimicrobial, antioxidant, antimutagenic activities, and phenolic compounds of Iris germanica. - Ind Crops Prod 61: 526-530.

[8] Chen, X. H., Gao, Y. B., Zhao, N. X. (2009): An AFLP analysis of genetic diversity and structure of Caragana microphylla populations in Inner Mongolia steppe, China. Biochem Syst Ecol. 37: 395-401.

[9] Chung, M. Y., López-Pujol, J., Lee, Y. M., Chung, M. G. (2014): Clonal and genetic structure of Iris odaesanensis and Iris rossii (Iridaceae): insights of the Baekdudaegan Mountains as a glacial refugium for boreal and temperate plants. - Plant Syst Evol. 02 Nov., online first.

[10] Claire, A. (1957): Irises: a gardener's encyclopedia. - Portland: Timber Press, pp. 11-13.

[11] Duffy, K. J., Scopece, G., Cozzolino, S. (2009): Ecology and genetic diversity of the dense-flowered orchid, Neotinea maculata, at the centre and edge of its range. - Ann Bot. 104: 507-516.

[12] Garrido, J. L., Fenu, G., Mattana, E. (2012): Bacchetta G. Spatial genetic structure of Aquilegia taxa endemic to the island of Sardinia. - Ann Bot. 109: 953-964.

[13] Hesham, A. A., Yan, W. G. (2010): Genetic diversity and relatedness of rice cultivars resistant to straighthead disorder. - Plant Breed 129: 304-312.

[14] Hong, Z., Jin, L., Yi-ping, X. (2013): Determination of genetic relationships between evergreen azalea cultivars in China using AFLP markers. - Zhejiang Univ.-Sci. B (Biomed \& Biotechnol) 14: 299-308.

[15] Huang, C. Q., Zhang, Y. F., Liu, G. D. (2012): Genetic diversity of Cynodon radiatus assessed by sequence-related amplified polymorphism markers. - Biochem Syst Ecol 40: $56-61$. 
[16] Isaza, L., Marulanda, M. L., López, A. M. (2012): Genetic diversity and molecular characterization of several Heliconia species in Colombia. - Genet Mol Res 11: 4552-4563.

[17] Jianab, S., Shib, S. (2009): Genetic variation in Heritiera littoralis (Malvaceae) from east and south Asia revealed by AFLP markers. - Plant Bios 143: S56-S62.

[18] Lin, H., Tao, Q. L., Zhang, J. J. (2010): Iris introduction of the latest international classification. - Garden Technol 118: 1-3.

[19] Liu, W. J. (2009): The introduction of Iris classification. - Chinese Flower Rep 8: 1.

[20] Marak, C. K., Laskar, M. A. (2010): Analysis of phenetic relationship between Citrus Indica Tanaka and a few commercially important citrus species by ISSR markers. - Sci Hortic 124: 345-348.

[21] Matus, I. A., Hayes, P. M. (2002): Genetic diversity in three groups of barley germplasm assessed by simple sequence repeats. - Genome 45: 1095-1106.

[22] Morales, R. G. F., Resende, J. T. V., Resende, F. V. (2013): Genetic divergence among Brazilian garlic cultivars based on morphological characters and AFLP markers. - Genet Mol Res 12: 270-281.

[23] Mou, S. H., Peng, Z. H., Qie, G. F. (2011): Genetic diversity of Iris determined by AFLP markers. - J North East Forest Univ. 39: 124-126.

[24] Poppendieck, H. H. (1983): Evolution and Classification of Seed Plants. - Prog Bot 45: 242-297.

[25] Qiao, L. X., Liu, H. Y., Guo, B. T. (2007): Molecular identification of 16 Porphyra lines using sequence-related amplified polymorphism markers. - Aquat Bot 87: 203-208.

[26] Rohlf, F. J. (2000): NYSYS-pc: numerical taxonomy and multivariate analysis system, version 2.1. - Exeter publications, Setauket.

[27] Shimizu, K., Miyabe, Y., Nagaike, H. (1999): Production of somatic hybrid plants between Iris ensata Thunb. and I. germanica. - Euphytica 107: 105-113.

[28] Talebi, M., Hajiahmadi, Z., Rahimmalek, M. (2011): Genetic diversity and population structure of four Iranian alfalfa populations revealed by sequence-related amplified polymorphism (SRAP) markers. - J Crop Sci Biotech 14: 173-178.

[29] Tang, S., Okashah, R. A., Knapp, S. J. (2010): Transmission ratio distortion results in asymmetric introgression in Louisiana Iris. - BMC Plant Biol 10: 48.

[30] Tatikonda, L., Wani, S. P., Kannan, S. (2009): AFLP-based molecular characterization of an elite germplasm collection of Jatropha curcas L., a biofuel plant. - Plant Sci. 76: 505-513.

[31] Tay, D. (2006): Herbaceous Ornamental Plant Germplasm Conservation and Use. - In: Anderson, N.O. (ed.) Flower Breeding and Genetics. Netherlands: Springer, pp. 113-175.

[32] Umezuruike, L. O., Dan, J., Nadiya, A. A. S. (2010): Analysis of genetic diversity in banana cultivars (Musa cvs.) from the South of Oman using AFLP markers and classification by phylogenetic, hierarchical clustering and principal component analyses. - Zhejiang Univ.-Sci. B (Biomed \& Biotechnol) 11: 332-341.

[33] Vieira, R. L., Nodari, R. O. (2007): Diversidade genética de cultivares de alho avaliada por marcadores RAPD. - Ciênc Rural 37: 51-57. 
[34] Vos, P., Hogers, R., Bleeker, M. (1995): AFLP: a new technique for DNA fingerprinting. - Nucl Acids Res 23: 4407-4414.

[35] Waddick, J. W., Zhao, Y. T. (1992): Iris of China. - Portland (USA): Timber Press.

[36] Wang, X. Z., Zhai, Q., Ling, X. Z. (2013): Effects of method and tissue on genomic DNA extraction of Ambrosia trifida. - Hubei Agricul Sci. 52: 1447-1449.

[37] Wanjala, B. W., Obonyo, M., Wachira, F. N. (2013): Genetic diversity in Napier grass (Pennisetum purpureum) cultivars: implications for breeding and conservation. - AOB Plants 5: 1-10.

[38] Yeh, F. C., Boyle, T. J. B. (1997): Population genetic analysis of co-dominant and dominant markers and quantitative traits. - Belg. J. Bot. 129:157.

[39] Zhang, M., Huang, S. Z. (2008): Analysis of Iris L. germplasm based on ISSR markers. Journal of Nanjing Agricultural University 31: 43-48.

[40] Zhang, L. (2010): The Iris application in American garden. - Garden 8: 38-41. (in Chinese).

[41] Zhao, Y. T. (1985): Flora of China. - Beijing: Science Press 16: 133-197. (in Chinese). 